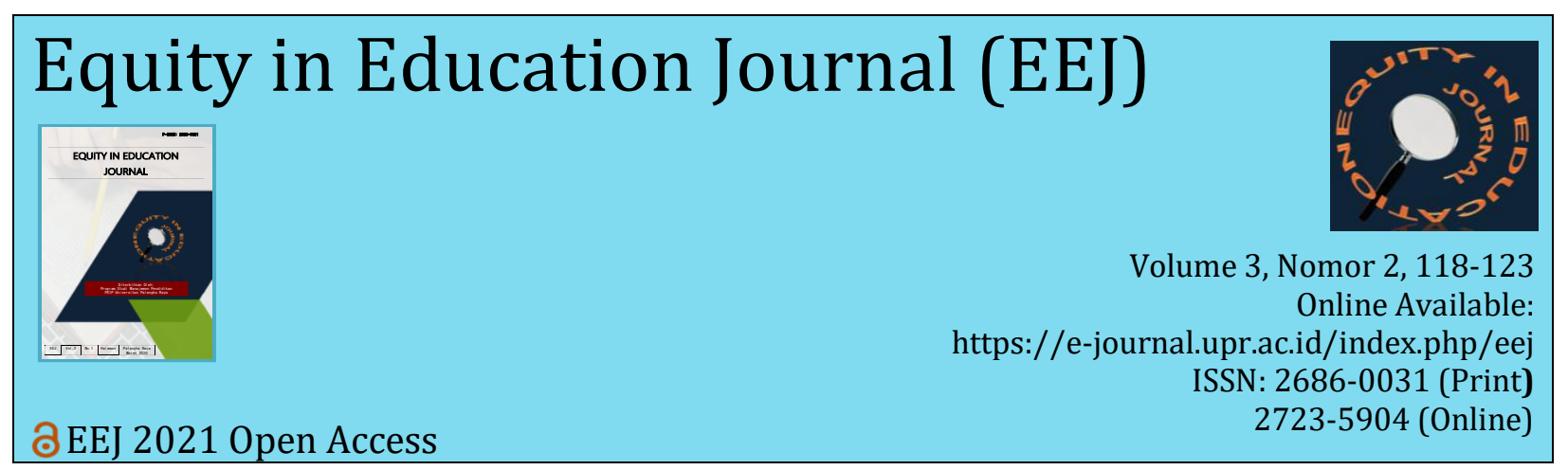

\title{
MANAJEMEN LABORATORIUM OTOMATISASI DAN TATA KELOLA PERKANTORAN DI SMKN 2 PALANGKA RAYA
}

\author{
Sahidah*, Piter Joko Nugroho, Sumarnie \\ FKIP, Universitas Palangka Raya, Palangka Raya
}

\begin{tabular}{ll}
\hline Info Artikel & \multicolumn{1}{c}{ Abstrak } \\
\hline Riwayat Artikel: & Penelitian ini bertujuan untuk mendeskripsikan tentang Manajemen \\
& Laboratorium Otomatisasi dan Tata Kelola Perkantoran di SMKN 2 Palangka \\
Diterima: 21 Juli 2021 & Raya. Penelitian ini menggunakan pendekatan kualitatif dengan rancangan studi \\
Direvisi: 19 Agustus 2021 & kasus. Sumber data meliputi: Kepala Sekolah, Waka. bidang Sarana dan \\
Disetujui: 2 September 2021 & prasarana, Ketua Program Keahlian dan Kepala Laboratorium. Teknik \\
& pengumpulan data melalui observasi, wawancara, dan studi dokumentasi. \\
Kata Kunci: & Analisis data menggunakan pola interaktif data, meliputi: pengumpulan data, \\
Manajemen, Laboratorium, & reduksi data, penyajian data, dan penarikan kesimpulan. Pengabsahan data \\
Ototatisasi dan Tata Kelola & menggunakan teknik triangulasi sumber dan metode. Hasil penelitian \\
Perkantoran. & menunjukkan bahwa pengelolaan laboratorium otomatisasi dan tata kelola \\
& perkantoran yang dilaksanakan dengan mendasarkan pada prinsip dasar \\
& manajemen dan mengacu pada standar pengelolaan sarana dan prasarana \\
& pendidikan menjadikan laboratorium berfungsi secara efektif dalam mendukung \\
& proses dan hasil belajar siswa secara optimal.
\end{tabular}

Korespondensi:

Sahidah*

FKIP, Universitas Palangka

Raya

E-mail:

sahidah412@gmail.com

\section{Abstract}

This study aims to describe the Automation and Office Management Laboratory at SMKN 2 Palangka Raya. This study used a qualitative approach with case study design. Data sources include: Principal, Deputy Principal for Infrastructure, Head of Expertise Program and Head of Laboratory. Data collection techniques through observation, interviews, and documentation studies. Data analysis used an interactive pattern of data, including: data collection, data reduction, data presentation, and drawing conclusions. Validation of data using triangulation of sources and methods. The results of this study showed that the Automation and Office Management Laboratory which is carried out based on the basic principles of management and refers to the management standards of educational facilities and infrastructure makes the laboratory function effectively in supporting the process and student learning outcomes optimally.

\section{PENDAHULUAN}

Pendidikan merupakan sektor terpenting dalam suatu bangsa karena dengan adanya pendidikan masyarakat dapat hidup secara berkualitas. Pendidikan sangat berpengaruh dalam pembangunan, baik itu dalam pengembangan sumber daya manusia, ekonomi, sosial, dan bahkan lebih banyak lagi peran pendidikan dalam pembangunan masyarakat, bangsa, dan negara (Green dkk, 2007). Kemendikbud (2017) menyatakan bahwa untuk meningkatkan kualitas pendidikan kejuruan adalah dengan meningkatkan sarana dan prasarana yang ada, mempekerjakan tenaga pendidik yang kompeten dalam bidangnya, dan memperbaiki mutu lulusan. Hal ini sesuai dengan Peraturan Pemerintah (PP) Nomor 19 Tahun 2005 tentang Standar Nasional Pendidikan BAB VII 
Pasal 42 ayat 1 dan 2 menyatakan: “(1) Setiap satuan pendidikan wajib memiliki sarana yang meliputi perabot, peralatan pendidikan, media pendidikan, buku dan sumber belajar lainnya, bahan habis pakai, serta perlengkapan lain yang diperlukan untuk menunjang proses pembelajaran yang teratur dan berkelanjutan, dan (2) Setiap satuan pendidikan wajib memiliki prasarana yang meliputi lahan, ruang kelas, ruang pimpinan satuan pendidikan, ruang pendidik, ruang tata usaha, ruang perpustakaan, ruang laboratorium, ruang bengkel kerja, ruang unit produksi, ruang kantin, instalasi daya dan jasa, tempat berolahraga, tempat beribadah, tempat bermain, tempat berkreasi, dan ruang/tempat lain yang diperlukan untuk menunjang proses pembelajaran yang teratur dan berkelanjutan". Mengingat begitu pentingnya sarana dan prasarana, maka sekolah diwajibkan untuk menyediakan fasilitas tersebut guna menunjang proses belajar mengajar.

Peraturan Menteri Pendidikan Nasional (Permendiknas) Nomor 40 Tahun 2008 tentang Standar Sarana dan prasarana SMK/MAK menyatakan bahwa SMK/MAK sekurang-kurangnya memiliki sarana dan prasarana yang dapat dikelompokkan menjadi ruang pembelajaran umum, ruang penunjang dan ruang pembelajaran khusus. Ruang pembelajaran khusus yang dimaksudkan pada Lampiran Permendiknas Nomor 40 tahun 2008 adalah ruang praktik kejuruan atau biasa disebut laboratorium. Laboratorium merupakan salah satu komponen yang mempunyai peranan penting dalam mencapai tujuan pendidikan. Laboratorium merupakan sarana yang dibutuhkan untuk memenuhi kebutuhan dalam melakukan praktikum (Muthohar, 2020), sekaligus sebagai salah satu solusi yang paling tepat untuk menambah keterampilan peserta didik khususnya di SMK (Lindayani, 2018); sehingga dalam upaya tersebut laboratorium harus dikelola sedemikian rupa agar dapat menjadi sarana untuk mendukung dan mempermudah penguasaan pengetahuan, melatih, dan mengembangkan keterampilan peserta didik (Ngestiyani, 2015).

Susilo (2018) menyatakan laboratorium yang dikelola dengan baik akan mendukung prestasi belajar siswa. Terdapat pengaruh positif ketersediaan dan pemanfaatan yang efektif pada alat-alat laboratorium terhadap prestasi akademik siswa di sekolah (Olufunke dalam Meillani \& Murwatiningsih, 2016); termasuk pada jurusan Otomatisasi dan Tata Kelola Perkantoran (OTKP), laboratorium OTKP (baca: dulu bernama Laboratorium Administrasi Perkantoran) sangat berperan dalam optimalisasi pengembangan keterampilan kognitif, afektif, dan psikomotor siswa (Mirnawati, 2019). Hasil dari pengelolaan laboratorium OTKP yang efektif dalam mendukung proses pembelajaran dan capaian prestasi siswa yang optimal, peneliti temukan pada jurusan OTKP di SMKN 2 Palangka Raya. Berbagai prestasi diraih oleh jurusan tersebut baik pada level provinsi maupun nasional, atara lain juara Lomba Keterampilan Siswa (LKS) Provinsi Kalimantan Tengah Tahun sekaligus mewakili Provinsi Kalimantan Tengah pada LKS di Jakarta dan Palembang, serta meraih prestasi 10 (sepuluh) besar hasil Ujian Sekolah Tahun 2018 di tingkat Nasional dengan tingkat kelulusan terbesar secara nasional.

Secara umum penelitian ini bertujuan untuk mendeskripsikan tentang Manajemen Laboratorium Otomatisasi dan Tata Kelola Perkantoran di SMKN 2 Palangka Raya sebagai jurusan yang memiliki laboratorium OTKP percontohan yang baik pada jenjang pendidikan kejuruan di Provinsi Kalimantan Tengah.

\section{METODE}

Penelitian ini merupakan penelitian kuantitatif dengan rancangan studi kasus. Moleong (2012) menyatakan bahwa penelitian kualitatif adalah tampilan yang berupa kata-kata lisan atau tertulis yang dicermati oleh peneliti, dan benda-benda yang diamati sampai detailnya agar dapat ditangkap makna yang tersirat dalam dokumen atau bendanya; sedangkan studi kasus adalah memahami suatu kasus, orang-orang tertentu atau situasi secara mendalam (Creswell, 2014). Sumber data dalam penelitian ini meliputi: Kepala Sekolah, Wakil Kepala Sekolah bidang Sarana dan prasarana, Ketua Program Keahlian dan Kepala Laboratorium. Teknik pengumpulan data melalui observasi, wawancara, dan studi dokumentasi. Analisis data menggunakan pola interaktif data dari Miles \& Huberman (2008), meliputi: pengumpulan data, reduksi data, penyajian data, 
dan penarikan kesimpulan. Pengabsahan data menggunakan teknik triangulasi sumber dan metode.

\section{HASIL DAN PEMBAHASAN \\ Perencanaan Laboratorium OTKP}

Berdasarkan hasil temuan penelitian diketahui bahwa perencanaan laboratorium OTKP merupakan tahap awal yang dilakukan oleh sekolah dalam melaksanakan kegiatan pengelolaan laboratorium. Perencanaan pengelolaan laboratorium OTKP di SMKN 2 Palangka Raya dilakukan dengan melalui tahapan: (1) rapat koordinasi yang dilakukan oleh seluruh personil sekolah yang terlibat mulai dari Kepala Sekolah, Wakil Kepala Sekolah bagian Sarana dan Prasarana, Wakil Kepala Sekolah bagian Kurikulum, Wakil Kepala Sekolah bagian Kesiswaan, Wakil Kepala Sekolah bagian Humas, Ketua Program Keahlian, Kepala Laboratorium dan pihak lainnya, (2) menganalisis kebutuhan sarana dan prasarana labotratorium, (3) menyusun rencana pengadaan sarana dan prasarana laboratorium, dan (4) melakukan pembelian barang yang dibutuhkan sekolah yang disesuaikan dengan anggaran APBN dan disalurkan melalui dana bos sesuai petunjuk teknis pengelolaan dana BOS.

Temuan penelitian tentang perencanaan pengelolaan laboratorium OTKP ini sejalan dengan syarat dan tahapan proses perencanaan yang diungkapkan oleh Barnawi \& Arifin (2012) bahwa dalam perencanaan sarana dan prasarana sekolah termasuk laboratorium hal-hal yang harus diperhatikan dan dilakukan sekolah meliputi: (1) penyusunan daftar kebutuhan, (2) estimasi biaya, (3) menetapkan skala prioritas, dan (4) penyusunan recana pengadaan". Melalui perencanaan sarana dan prasarana laboratorium yang baik akan memudahkan kegiatan pengadaan barang sesuai dengan anggaran yang tersedia di sekolah (Bafadal, 2014).

\section{Pengorganisasian Laboratorium OTKP}

Berdasarkan hasil temuan penelitian diketahui bahwa pengorganisasian pengelolaan laboratorium OTKP dilakukan dengan menetapkan struktur organisasi beserta tugas dan tanggung jawab dari masing-masing unsur yang terlibat dalam pengelolaan laboratorium. Unsur-unsur yang terdapat dalam struktur organisasi pengelola laboratorium terdiri dari: Ketua Program Keahlian, Kepala Laboratorium, Sekertaris, Bendahara, Wali Kelas dan Guru Mata Pelajaran Keahlian yang mempunyai tugas dan tanggung jawab sesuai dengan kewenangannya masing-masing. Pembagian tugas dan tanggung jawab secara jelas tersebut ditujukan untuk terciptanya kejelasan tugas dan fungsi dari setiap unsur yang terlibat sekaligus sehingga semua proses pengelolaan laboratorium saling selaras dan saling terkoordinasi dengan bai kantar unsur yang terlibat.

Temuan penelitian tentang pengorganisasian laboratorium OTKP ini sejalan dengan pendapat Sudirman (2011) yang menjelaskan bahwa pengorganisasian merupakan penyusunan struktur formal kewenangan yakni penjabaran dan menetapkan rincian pembagian tugas kerja, wewenang dan mengkoordinasikannya untuk mencapai tujuan. Organisasi laboratorium harus memiliki struktur organisasi, deskripsi pekerjaan, dan susunan personalia yang mengelola labaoratorium tersebut (Sitorus \& Sutiani, 2013). Organizing atau Struktur Organisasi dan Tata Kerja (SOTK) berfungsi untuk memfasilitasi dan mendukung pencapaian misi lembaga. Struktur organisasi dan tata kerja dibuat agar tidak terjadi tumpang tindih di dalam pencapaian tujuan sebuah organisasi (Muhammad dkk, 2018). Melalui pengorganisasian yang baik akan menghasilkan bentuk organisasi yang baik, mulai dari sistem kerja, struktur, sumber daya hingga aspek lainnya (Rahman, 2015).

\section{Pemeliharaan Laboratorium OTKP}

Berdasarkan hasil temuan penelitian diketahui bahwa pemeliharaan dalam pengelolaan laboratorium OTKP menjadi tanggung jawab Wakil Kepala Sekolah bagian Sarana dan Prasarana dibantu oleh pihak pengelola laboratorium. Proses pemeliharaan laboratorium OTKP, peralatan yang dipinjam setelah digunakan dikembalikan pada tempat semula secara lengkap. Dalam proses 
pemeliharaan ini juga dilakukan dengan melaporkan peralatan yang rusak melalui pengecekan secara langsung untuk mengetahui keadaan peralatan rusak ringan atau rusak berat (tidak dapat diperbaiki lagi), melakukan penyingkiran terhadap sarana dan prasarana yang keadaannya rusak berat atau tidak dapat diperbaiki lagi dengan mempertimbangkan faktor-faktor pemusnahan ditinjau dari segi uang. Penyingkiran sarana dan prasarana tersebut dilakukan oleh pihak laboratorium disaksikan Kepala Sekolah, Wakil Kepala Sekolah bagian Sarana dan prasarana, Pejabat Pemeritah (dalam hal ini Dinas Pendidikan Provinsi Kalimantan Tengah serta pihak apparat Kepolisian, dengan cara dibakar, dikubur dan sebagainya, kemudian kepala sekolah menghapuskan barang dari buku inventaris.

Heizer \& Render (2011) menyatakan pemeliharaan adalah segala kegiatan yang di dalamnya untuk menjaga sistem peralatan agar bekerja dengan baik. Pemeliharaan sarana dan prasarana pendidikan sangat penting agar sarana dan prasarana pendidikan terpelihara dengan baik dan tepat. Semua pihak sekolah baik Kepala Sekolah, Peserta Didik, maupun Tenaga Pendidik dan Kependidikan berkewajiban untuk melakukan pemeliharaan sarana dan prasarana dengan baik secara bersama-sama. Bafadal (2014) menyatakan dalam pemeliharan sarana dan prasarana pendidikan termasuk laboratorium, dapat dilakukan melalui 4 (empat) macam pemeliharaan, yaitu: (1) pemeliharaan bersifat pengecekan, (2) pemeliharaan bersifat pencegahan, (3) pemeliharaan bersifat perbaikan ringan, dan (4) pemeliharaan bersifat perbaikan berat. Sedangkan ditinjau dari waktu perbaikannya ada dua macam pemeliharaan, yaitu: (1) pemeliharaan seharihari, (2) pemeliharaan berkala". Jika sarana dan prasarana pendidikan di sekolah termasuk laboratorium terpelihara dengan baik dan benar, maka akan dapat berfungsi dan digunakan sesuai dengan yang seharusnya dan tentu akan berdampak pada peningkatan kualitas pendidikan (Suliyarti, 2019).

\section{Pengawasan Laboratorium OTKP}

Berdasarkan hasil temuan penelitian diketahui bahwa pengawasan sarana dan prasarana sekolah termasuk sarana dan prasarana laboratorium OTKP dilakukan oleh semua pihak yang bertanggung jawab atas pengelolaan sarana dan prasarana yang ada di sekolah, meliputi: Wakil Kepala Sekolah bagian Sarana dan prasarana, Kepala Laboratorium, Ketua Program Keahlian, dan Guru Mata Pelajaran Keahlian, dimana pihak-pihak tersebut bertanggung jawab dan melaporkan hasil pengawasan kepada Kepala Sekolah untuk selanjutnya sekolah akan meindaklanjuti hasil dari pengawasan tersebut untuk perbaikan kebijakan sekolah ke depan. Pengawasan laboratorium kegiatan dilaksanakan baik secara prefentif maupun represif. Khusus pada kegiatan pengawasan prefentif, dilaksanakan minimal 1 bulan sekali dengan cara melakukan pendataan barang yang dipinjam, dipakai, dan dikembalikan pada tempat semula sehingga berbagai kemungkinan terjadinya kerusakan maupun peralatan yang hilang dapat diminimalisir; sedangkan pengawasan yang bersifat represif dilakukan di akhir setiap tahun ajaran dan disusun sebagai laporan kondisi sarana dan prasarana sekolah secara keseluruhan.

Nurabadi (2013) menyatakan pengawasan (control) terhadap sarana dan prasarana pendidikan (termasuk laboratorium) sekolah merupakan usaha memelihara dan memanfaatkan sarana dan prasarana sekolah dengan sebaik mungkin demi keberhasilan proses pembelajaran di sekolah. Kegiatan pengawasan dan pengendalian harus dilakukan secara kontinyu, obyektif, transparan, dan akuntabel (Danim \& Danim, 2011). Temuan penelitian terkait pengawasan secara periodik yang ditujukan untuk meminimalisir berbagai kemungkinan terjadinya kerusakan maupun peralatan yang hilang sejalan dengan pendapat Julitriarsa \& Suprihanto (2001) bahwa pengawasan terhadap sarana dan prasarana dapat dilakukan secara preventif dan represif. Pengawasan prefentif dilakukan pada waktu sebelum terjadinya penyimpangan atau kesalahan, sedangkan pengawasan represif dilakukan pada waktu sudah terjadi penyimpangan atau kesalahan. Pengawasan preventif dapat dilakukan dengan mengadakan peraturan-peraturan atau menyusun tata tertib penggunaan laboratorium administrasi perkantoran; sedangkan pengawasan represif dapat dilakukan setelah pekerjaan dilakukan dimana pengawasan ini menurut adanya 
evaluasi yang bertujuan untuk meningkatkan mutu laboratorium (Manullang, 2008). Seluruh kegiatan pengelolaan sarana dan prasarana pendidikan tidak bisa berjalan sendiri-sendiri tanpa dikendalikan dan diawasi, artinya setiap kegiatan masing-masing akan dimonitoring setiap saat oleh pimpinan organisasi serta diperhatikan kerjasamanya satu sama lain. Pengawasan bukan merupakan suatu pengaturan yang kaku dan akan membatasi ruang gerak masing-masing fungsi pengelolaan, melainkan merupakan koordinasi serta akselerasi bagi seluruh fungsi pengelolaan, sehingga pemborosan waktu, tenaga dan biaya dapat dihindarkan (Rahmafitri \& Afriansyah, 2019).

\section{SIMPULAN}

Berdasarkan hasil penelitian dan pembahasan dapat disimpulkan bahwa laboratorium OTKP SMKN 2 Palangka Raya yang berfungsi sebagai sarana untuk mendukung dan mempermudah penguasaan pengetahuan, dan mengembangkan keterampilan kognitif, afektif, serta psikomotor peserta didik dalam kompetensi bidang administrasi perkantoran yang dikelola dengan efektif dengan mendasarkan pada prinsip dasar manajemen mulai dari perencanaan, pengorganisasian, pemeliharaan dan pengawasan serta mengacu pada standar pengelolaan sarana dan prasarana pendidikan, membawa dampak positif terhadap capaian prestasi peserta didik dan sekolah baik pada level provinsi maupun nasional.

\section{UCAPAN TERIMA KASIH}

Ucapan terima kasih penulis sampaikan kepada pihak SMKN 2 Palangka Raya yang telah memberikan izin dan kemudahan selama proses penelitian ini berlangsung, serta Redaksi Equity in Education Journal (EEJ) yang telah memberikan kesempatan artikel penulis dapat dimuat dalam jurnal ini.

\section{DAFTAR PUSTAKA}

Bafadal, I. (2014). Manajemen Perlengkapan Sekolah Teori dan Aplikasinya. Jakarta : PT Bumi Aksara.

Barnawi \& M. Arifin. (2012). Manajemen Sarana dan Prasarana Sekolah. Jogyakarta: Ar-Ruzz Media.

Creswell, J. W. (2014). Research Design: Qualitative, Quantitative and Mixed Methods Approaches: Fourth edition. Thousand Oaks, CA: Sage Publications.

Danim, S., \& Danim, Y. (2011). Administrasi Sekolah dan Manajemen Kelas. Bandung: Pustaka Setia.

Green, A., Little, A. W., Kamat, S. G., Oketch, M., \& Vickers, E. (2007). Education and Development in a Global Era: Strategies for 'Successful Globalisation'. London: University of London.

Heizer, J., \& Render, B. (2011). Manajemen Operasi. Jakarta: Salemba Empat.

Julitriarsa, D., \& Suprihanto, J. (2001). Manajemen Umum: sebuah Pengantar. Yogyakarta: BPFE.

Kementerian Pendidikan dan Kebudayaan (Kemendikbud). (2017). Revitalisasi SMK untuk Produktivitas dan Daya Saing Bangsa. Diterima dari https://www.kemdikbud.go.id/main/blog/2017/05/revitalisasi-smk-untuk-produktivitasdan-daya-saing-bangsa.

Lindayani. (2018). Pengaruh Pemanfaatan Laboratorium terhadap Prestasi Belajar Peserta Didik pada Mata Pelajaran Kearsipan Kompetensi Keahlian Otomatisasi dan Tata Kelola Perkantoran di SMK Negeri 1 Barru. Skripsi tidak Dipublikasikan. Makassar: Universitas Negeri Makassar, Fakultas Ilmu Sosial.

Manullang, M. (2008). Dasar-Dasar Manajemen. Yogyakarta: Penerbit Gadjah Mada University Press.

Meillani, P., \& Murwatiningsih. (2016). Pengaruh Pemanfaatan Laboratorium Hasil Belajar Siswa 
123 Equity in Education Journal (EEJ), Vol. 3, No. 2, Oktober 2021

Program Keahlian Perkantoran di SMK. Economics Education Analysis Journal, 5(1).

Miles, M. B., \& Huberman, A. M. (2008). Analisis Data Kualitatif: Buku Sumber tentang MetodeMetode Baru. Jakarta: UI Press.

Mirnawati. (2019). Peran Laboratorium Perkantoran pada Mata Pelajaran Kearsipan Kelas X Kompetensi Keahlian Administrasi Perkantoran di SMK Nasional Makassar. Skripsi tidak Dipublikasikan. Makassar: Universitas Negeri Makassar, Fakultas Ilmu Sosial.

Moleong, L. J. (2012). Metode Penelitian Kualitatif. Bandung: Remaja Rosdakarya.

Muhammad, C. I., Santoso, M. B., \& Zainudin, M. (2018). Penetapan Struktur Organisiasi dan Tata Kerja pada Organisasi Pelayanan Sosial Rumah Cemara Kota Bandung. Prosiding Penelitian dan Pengabdian kepada Masyarakat, 4(3), 424-432.

Muthohar, A. (2020). Pengelolaan Laboratorium Administrasi Perkantoran sebagai Penunjang Perkuliahan. Skripsi tidak Dipublikasikan. Semarang: Universitas Negeri Semarang, Fakultas Ekonomi, Jurusan Pendidikan Ekonomi.

Ngestiyani, R. (2015). Pengelolaan Laboratorium Administrasi Perkantoran di SMK Muhammadiyah 1 Wates. Skripsi tidak Dipublikasikan. Yogayakarta: Universitas Negeri Yogyakarta, Fakultas Ekonomi, Program Studi Administrasi Perkantoran.

Nurabadi, A. (2013). Manajemen Sarana dan Prasarana Pendidikan. Malang: Penerbit Universitas Negeri Malang.

Peraturan Menteri Pendidikan Nasional (Permendiknas) Nomor 40 Tahun 2008 tentang Standar Sarana dan prasarana SMK/MAK

Peraturan Pemerintah (PP) Nomor 19 Tahun 2005 tentang Standar Nasional Pendidikan.

Rahmafitri, M., \& Afriansyah, H. (2019). Administrasi Sarana dan Prasarana Pendidikan. Diterima dari https://osf.io/preprints/inarxiv/jra8x/.

Rahman, F. (2015). Manajemen Organisasi dan Pengorganisasian dalam Perspektif Al-Qur'an dan Hadith. Ulumuna: Jurnal Studi Keislaman, 1(2).

Sitorus, M., \& Sutiani, A. (2013). Pengelolaan dan Manajemen Laboratorium Kimia. Yogyakarta: Graha Ilmu.

Sudirman, D. W. (2011). Pengelolaan Laboratorium Pendidikan Administrasi Perkantoran. Efisiensi, XI(2). Doi: https://doi.org/10.21831/efisiensi.v11i2.3992.

Suliyarti, R. (2019). Manajemen Pemeliharaan Sarana dan Prasarana Pendidikan untuk Meningkatkan Kualitas Pendidikan. Diterima dari https://osf.io/preprints/inarxiv/qj3x4/download.

Susilo, B. (2018). Manajemen Laboratorium dalam Upaya Mewujudkan Prestasi Belajar IPA. Media Manajemen Pendidikan, 1(2). 